\title{
CARACTERIZAÇÃO MORFOLÓGICA DE ISOLADOS DE Trichoderma harzianum
}

Gesiane Ribeiro Guimarães ${ }^{1}$, Carolina dos Santos Galvão ${ }^{2}$, Sueli Corrêa Marques de Mello ${ }^{3}$, Daniel Diego Costa Carvalho ${ }^{4}$

${ }^{1}$ Tecnóloga em Gestão Ambiental, mestre em Produção Vegetal, Universidade Estadual de Goiás, Ipameri, Goiás.

${ }^{2}$ Engenheira agrônoma, Universidade Estadual de Goiás, Ipameri, Goiás.

${ }^{3}$ Doutora em Fitopatologia, Pesquisadora A, Embrapa Recursos Genéticos e Biotecnologia, Brasília, Distrito Federal.

${ }^{4}$ Doutor em Fitopatologia, Professor DES V nível 1, Universidade Estadual de Goiás, Ipameri, Goiás. Email: daniel.carvalho@ueg.br

RESUMO: Variações morfológicas ou genéticas entre isolados de Trichoderma harzianum tem sido recentemente pesquisadas em muitos trabalhos, pois T. harzianum é considerado um agregado de espécies, agrupadas com base em padrões de ramificação de conidióforos e características particulares às fiálides e conídios. O objetivo deste trabalho foi verificar se existem variações micromorfológicas entre cinco isolados de T. harzianum, previamente identificados por sequenciamento das regiões ITS-1 e ITS- 4 do rDNA. Para obtenção dos dados, parte do micélio desenvolvido a $25^{\circ} \mathrm{C}$, em meio BDA e ausência de luz, por sete dias, foi removido para confecção de lâminas semi-permanentes. As fiálides tiveram dimensões de 3,7 - 8,2 x 1,4 - 3,8 $\mu \mathrm{m}(5,5$ x 2,3 $\mu \mathrm{m})$, com relação comprimento/largura (C/L) de 2,1 2,4 , enquanto que os conídios eram subglobosos e ovais com medidas médias de 1,6 - 3,6 x $1,5-3,2 \mu \mathrm{m}(2,6 \times 2,1 \mu \mathrm{m})$ e relação $\mathrm{C} / \mathrm{L}$ de 1,02 - 1,11. Embora seja um agregado de espécies, não houve variações morfológicas no formato ou nas medidas das estruturas mensuradas. As lâminas foram depositadas no Laminário Fitopatológico da Universidade Estadual de Goiás.

Palavras-chave: Taxonomia de fungos. Algodoeiro. Fungos do solo.

\section{MORPHOLOGICAL CHARACTERIZATION OF Trichoderma harzianum ISOLATES}

\begin{abstract}
Morphological and genetic variations among Trichoderma harzianum isolates has been recently researched in several studies, since T. harzianum comprises in a specie aggregate, grouped based on conidiophore branching patterns and particular features of phialides and conidia. The objective of this study was to verify if there are a micromorphological variation among five $T$. harzianum isolates, previously identified by sequencing the ITS-1 and ITS-4 rDNA regions. To obtain the data, part of the mycelium grown at $25^{\circ} \mathrm{C}$ on PDA medium and in the dark, was removed from seven-day-old colonies to prepare semi-permanent microscope slides. The phialides showed $3.7-8.2 \times 1.4-3.8$ $\mu \mathrm{m}(5.5 \times 2.3 \mu \mathrm{m})$, with length/width ratio (L/W) of $2.1-2.4$, while the conidia were subglobose and oval shape with average measure of $1.6-3.6 \times 1.5-3.2 \mu \mathrm{m}(2.6 \times 2.1 \mu \mathrm{m})$ and
\end{abstract}

Cultura Agronômica, Ilha Solteira, v.25, n.2, p.131-136, 2016 
$\mathrm{L} / \mathrm{W}$ ratio of $1.02-1.11$. Although an aggregate species, there were not morphological variations in the shape or average of the measured structures. The semi-permanent slides were stored in the Goias State University Plant Disease Slide Collection.

Key words: Fungi taxonomy. Cotton plant. Soil

fungi.

\section{INTRODUÇÃO}

Um dos componentes iniciais relativos a experimentos com o fungo Trichoderma compreendem a sua identificação, seja por meio de sequenciamento de DNA ou baseada em caracteres morfológicos (CHAVERRI et al., 2003; ABD-ELSALAM et al., 2010; KAMALA et al., 2015). Especificamente, os marcadores de DNA tornaram-se uma ferramenta poderosa para o estudo de taxonomia e análise molecular de organismos (LÓPEZ-MONDÉJAR et al., 2011). Embora a caracterização molecular seja uma fonte imensa de dados que pode auxiliar os cientistas na identificação de espécies de Trichoderma (GAJERA; VAKHARIA, 2010), a taxonomia de espécies deste gênero tem sido definida com base nas suas características morfológicas, principalmente o tamanho e forma de conídios e fiálides (SAMUELS et al., 2009; MUTHUKUMAR et al., 2011).

As características morfológicas de colônias, bem como a velocidade de crescimento micelial a diferentes temperaturas foram utilizadas por PARK et al. (2005b). Para caracterização de isolados, entretanto, diferenças entre sete diferentes espécies (Trichoderma sp.1, Trichoderma sp.2, T. harzianum, T. virens, T. atroviride, T. citrinoviride e $T$. longibrachiatum) foram evidenciadas mediante mensuração de caracteres micromorfológicos.

Variações morfológicas ou genéticas entre isolados de $T$. harzianum continuam sendo estudadas por vários autores (PARK et al., 2005a, b; SHARMA et al., 2009; ADBELSALAM et al., 2010; KAMALA et al., 2015). Segundo GRONDONA et al. (1997), a espécie T. harzianum pode ser dividida em três, quatro ou até cinco subgrupos específicos, dependendo das estirpes e características avaliadas. Deste modo, variações morfológicas entre isolados de uma mesma espécie de Trichoderma podem ocorrer, visto que as características morfológicas são facilmente alteradas por influências ambientais (PARK et al., 2005b).

Recentemente, o potencial de cinco isolados de $T$. harzianum como agentes de controle biológico de patógenos habitantes do solo foi observado em laboratório e em campo por GUIMARÃES et al. (2014), CARVALHO et al. (2014) e CARVALHO et al. (2015). Entretanto, pouco se conhece sobre as variações morfológicas entre estes isolados. Assim, o objetivo deste trabalho foi realizar a caracterização micromorfológica de cinco isolados de T. harzianum, previamente identificados por sequenciamento das regiões ITS-1 e ITS- 4 do rDNA, para verificar se existem variações morfológicas entre estes isolados.

Cultura Agronômica, Ilha Solteira, v.25, n.2, p.131-136, 2016 


\section{MATERIAL E MÉTODOS}

Cinco isolados de T. harzinaum (CEN287, CEN288, CEN289, CEN290 e CEN316) utilizados neste trabalho pertencem a Coleção de Fungos para Controle Biológico de Fitopatógenos e Plantas Daninhas, da Embrapa Recursos Genéticos e Biotecnologia, Brasília, Distrito Federal, Brasil. Os ensaios foram realizados na Universidade Estadual de Goiás (UEG), Ipameri, Goiás, Brasil. As culturas armazenadas em nitrogênio líquido foram recuperadas em meio Batata-Dextrose-Ágar (BDA; batata $200 \mathrm{~g} \mathrm{~L}^{-1}$, dextrose $20 \mathrm{~g} \mathrm{~L}^{-1}$, e ágar $20 \mathrm{~g} \mathrm{~L}^{-1}$ a $\mathrm{pH}$ 6,5).

Para obtenção dos dados micromorfológicos, parte do micélio de colônias desenvolvido a $25^{\circ} \mathrm{C}$ em meio BDA e ausência de luz, após sete dias de incubação, foi removido para confecção de lâminas semi-permanentes. Estas foram preparadas empregando-se o corante azul de algodão como meio de montagem. Imagens das estruturas micromorfológicas foram capturadas com a utilização do microscópio LEICA DM500 e as medições das estruturas (40 medições para cada estrutura) foram feitas pelo uso do software LAS EZ. 2.0 (100x). As lâminas foram depositadas no Laminário Fitopatológico, da Universidade Estadual de Goiás.

Os dados relativos às medidas das estruturas fúngicas foram submetidos à análise de variância com auxílio do programa SISVAR 5.3 (FERREIRA, 2011), para obtenção do coeficiente de variação para o comprimento e largura dos conídios.

\section{RESULTADOS E DISCUSSÃO}

As características micromorfológicas dos cinco isolados de T. harzianum são descritos na Tabela 1. As fiálides mostraram dimensões de 3,7 - 8,2 x 1,4-3,8 $\mu \mathrm{m}(5,5 \times 2,3 \mu \mathrm{m})$, com relação comprimento/largura (C/L) de 2,1 - 2,4. Estas medidas estão em conformidade com Park et al. (2005b) que, trabalhando com um isolado-tipo de T. harzianum ocorrente em substrato para cultivo de cogumelos, encontraram medidas muito próximas: $3,5-7,6 \mathrm{x}$ $1,8-3,4 \mu \mathrm{m}(5,4 \times 2,6 \mu \mathrm{m})$ e relação $\mathrm{C} / \mathrm{L}$ de 2,1. Os valores publicados por Samuels et al. (2009): 6,5 - 6,7 x 1,6 - 4,5 $\mu \mathrm{m}$ (C/L de 2,1 - 2,2), são menos variáveis, porém também dentro dos intervalos verificados no presente trabalho.

Tabela 1. Características micromorfológicas de isolados de Trichoderma harzianum (CEN287, CEN288, CEN289, CEN290 e CEN316) ${ }^{(\text {a) }}$

\begin{tabular}{lllll}
\hline Isolados & \multicolumn{3}{c}{ Fiálides } & \multicolumn{2}{c}{ Conídios } \\
\cline { 2 - 5 } & Tamanho $(\mu \mathrm{m})$ & $\mathrm{C} / \mathrm{L}^{(\mathrm{b})}$ & Tamanho $(\mu \mathrm{m})$ & ${\mathrm{C} / \mathrm{L}^{(\mathrm{b})}}$ \\
\hline CEN287 & $3,8-7,2 \times 1,4-3,2(5,3 \times 2,3)$ & 2,4 & $1,8-3,2 \times 1,8-2,7(2,4 \times 2,1)$ & 1,10 \\
CEN288 & $3,8-8,2 \times 1,6-2,8(5,3 \times 2,3)$ & 2,3 & $2,0-3,6 \times 1,8-3,0(2,5 \times 2,3)$ & 1,11 \\
CEN289 & $4,0-6,9 \times 1,6-3,3(5,5 \times 2,4)$ & 2,3 & $1,6-3,2 \times 1,5-3,2(2,4 \times 2,2)$ & 1,08 \\
CEN290 & $4,2-6,6 \times 1,8-3,0(5,5 \times 2,5)$ & 2,2 & $2,0-2,8 \times 1,7-3,0(2,4 \times 2,3)$ & 1,02 \\
CEN316 & $3,7-7,0 \times 2,0-3,8(5,5 \times 2,6)$ & 2,1 & $2,0-2,9 \times 2,0-2,8(2,6 \times 2,4)$ & 1,06 \\
\hline
\end{tabular}

${ }^{(a)}$ Valores médios obtidos a partir de 40 unidades de cada característica.

(b) Relação entre o comprimento e a largura.

Cultura Agronômica, Ilha Solteira, v.25, n.2, p.131-136, 2016 
Os cinco isolados de $T$. harzianum apresentaram conídios subglobosos e ovais com medidas médias de 1,6 - 3,6 x 1,5 - 3,2 $\mu \mathrm{m}(2,6$ x 2,1 $\mu \mathrm{m})$ e relação C/L de 1,02 - 1,11. De forma análoga, estes valores seguem muito fiéis aos encontrados por Park et al. (2005b): 1,8 $-3,3 \times 1,7-3,2 \mu \mathrm{m}(2,5 \times 2,3 \mu \mathrm{m})(\mathrm{C} / \mathrm{L}$ de 1,13) e por Samuels et al. (2009): 2,0 - 5,0 x $1,8-4,0 \mu \mathrm{m}(\mathrm{C} / \mathrm{L}$ de $1,1-1,2)$.

A análise de sequência das regiões ITS1 e 2 do rDNA tem sido particularmente viável para a caracterização do gênero Trichoderma ao nível de espécie (SAMUELS et al., 2002). Neste sentido, após identificação molecular dos isolados CEN, atenção foi dada, no presente trabalho, para a caracterização destes, com vistas a verificar variações morfológicas entre os isolados.

De acordo com Shalin et al. (2006), T. harzianum é um agregado de espécies, agrupadas com base em padrões de ramificação de conidióforos (ramificações laterais curtas) e fiálides curtas e infladas. Embora seja um agregado de espécies, não foram vistas variações morfológicas nas medidas das estruturas mensuradas dos isolados CEN (Tabela 1). Uma explicação para isso reside no fato de estes isolados pertencerem a um único bioma (Cerrado) e provenientes do solo de uma mesma localidade (solo de cultivo de algodão, Planaltina, DF, Fazenda Cooperbrás, Núcleo Rural do Rio Preto).

Para Sharma et al. (2009), é possível que as variantes de $T$. harzianum surjam a partir de recombinantes durante a reprodução sexual do fungo. No entanto, uma diversidade genética entre isolados seria possível de obter se fossem analisadas populações de diferentes localidades de uma grande região, ou mesmo de um país, indicando que a migração e reprodução sexual desempenham papel importante na dinâmica populacional de $T$. harzianum (CHAVERRI et al., 2003).

Os isolados de $T$. harzianum apresentaram coeficientes de variação relativamente elevados para o comprimento (CEN287: 12,70\%; CEN288: 14,93\%; CEN289: 15,99\%; CEN290: 9,31\% e CEN316: 9,60\%) e largura (CEN287: 10,89\%; CEN288: 14,14\%; CEN289: 17,44\%; CEN290: 10,69\% e CEN316: 8,26\%) dos conídios. Em outro fungo Hyphomycetes, Guimarães e Carvalho (2014), encontraram coeficientes de variação menores para conídios de Cladosporium herbarum $(9,23$ e 3,72\% para o comprimento e largura, respetivamente). Embora tenha sido verificado coeficiente de variação de até $17,44 \%$ na largura dos conídios de um isolado de $T$. harzianum, não houve diferença entre os isolados, uma vez que os valores médios para comprimento e largura de conídios e fiálides não foram significativos.

\section{CONCLUSÃO}

Não há variações morfológicas no formato e nas medidas das estruturas (fiálides e conídios) mensuradas nos isolados de T. harzianum. 


\section{AGRADECIMENTOS}

Os autores agradecem ao apoio oferecido pelo Programa de Bolsa de Incentivo à Pesquisa e Produção Científica (PROBIP) da Universidade Estadual de Goiás (UEG) e a Coordenação de Aperfeiçoamento de Pessoal de Nível Superior (CAPES), por uma bolsa de mestrado.

\section{REFERÊNCIAS BIBLIOGRÁFICAS}

ABD-ELSALAM, K. A.; ALMOHIMEED, I.; MOSLEM, M. A.; BAHKALI, A. H. M13microsatellite PCR and rDNA sequence markers for identification of Trichoderma (Hypocreaceae) species in Saudi Arabian soil. Genetics and Molecular Research, Ribeirão Preto, v. 9, n. 4, p.2016-2024, 2010.

CARVALHO, D. D. C.; LOBO JUNIOR, M.; MARTINS, I.; INGLIS, P. W.; MELLO, S. C. M. Biological control of Fusarium oxysporum f. sp. phaseoli by Trichoderma harzianum and its use for common bean seed treatment. Tropical Plant Pathology, New York, v. 39, n. 5, p.384-391, 2014.

CARVALHO, D. D. C.; MELLO, S. C. M.; MARTINS, I.; LOBO JUNIOR, M. Biological control of Fusarium wilt on common beans by in-furrow application of Trichoderma harzianum. Tropical Plant Pathology, New York, v. 40, n. 6, p.375-381, 2015.

CHAVERRI, P.; CASTLEBURY, L. A.; OVERTON, B. E.; SAMUELS, G. J. Hypocrea/Trichoderma: species with conidiophore elongations and green conidia. Mycologia, Lawrence, v. 95, n. 6, p.1100-1140, 2003.

FERREIRA, D. F. Sisvar: a computer statistical analysis system. Ciência e Agrotecnologia, Lavras, v. 35, n. 6, p.1039-1042, 2011.

GAJERA, H. P.; VAKHARIA, D. N. Molecular and biochemical characterization of Trichoderma isolates inhibiting a phytopathogenic fungi Aspergillus niger van Tieghem. Physiological and Molecular Plant Pathology, London, v. 74, n. 3, p.274-282, 2010.

GRONDONA, I.; HERMOSA, M. R.; TEJADA, M.; GOMIS, M. D.; MATEOS, P. F.; BRIDGE, P.; MONTE, E.; GARCIA-ACHA, I. Physiological and biochemical characterization of Trichoderma harzianum, a biological control agent against soilborne fungal plant pathogens. Applied and Environmental Microbiology, Washington, v. 63, n. 8, p. 3189-3198, 1997.

GUIMARÃES, G. R.; CARVALHO, D. D. C. Incidência e caracterização morfológica de Cladosporium herbarum em feijão comum cv. 'Pérola'. Revista Brasileira de Biociências, Porto Alegre, v. 12, n. 3, p.137-140, 2014.

GUIMARÃES, G. R.; PEREIRA, F. S.; MATOS, F. S.; MELLO, S. C. M.; CARVALHO, D. D. C. Suppression of seed borne Cladosporium herbarum on common bean seed by Trichoderma harzianum and promotion of seedling development. Tropical Plant Pathology, New York, v. 39, n. 5, p.401-406, 2014.

Cultura Agronômica, Ilha Solteira, v.25, n.2, p.131-136, 2016 
KAMALA, T. H.; DEVI, S. I.; SHARMA, K. C.; KENNEDY. K. Phylogeny and taxonomical investigation of Trichoderma spp. from Indian region of Indo-Burma biodiversity hot spot region with special reference to Manipur. BioMed Research International, New York, v. 2015, p.1-21, 2015.

LÓPEZ-MONDÉJAR, R.; ROS, M.; PASCUAL, J. A. Mycoparasitism-related genes expression of Trichoderma harzianum isolates to evaluate their efficacy as biological control agent. Biological Control, San Diego, v. 56, n. 1, p.59-66, 2011.

MUTHUKUMAR, A.; ESWARAN, A.; SANJEEVKUMAS, K. Exploitation of Trichoderma species on the growth of Pythium aphanidermatum in chili. Brazilian Journal of Microbiology, São Paulo, v. 42, n. 4, p.1598-1607, 2011.

PARK, M. S.; SEO, G. S.; BAE, K. S.; YU, S. H. Characterization of Trichoderma spp. associated with green mold of oyster mushroom by PCR-RFLP and sequence analysis of ITS regions of rDNA. The Plant Pathology Journal, Suwon, v. 21, n. 3, p.229-236, 2005. (a)

PARK, M. S.; SEO, G. S.; LEE, K. H.; BAE, K. S.; YU, S. H. Morphological and cultural characteristics of Trichoderma spp. associated with green mold of oyster mushroom in Korea. The Plant Pathology Journal, Suwon, v. 21, n. 3, p.221-228, 2005. (b)

SAMUELS, G. J.; CHAVERRI, P.; FARR, D. F.; McCRAY, E. B. Trichoderma Online, Systematic Mycology and Microbiology Laboratory, ARS, USDA. Disponível em http://nt.ars-grin.gov/taxadescriptions/keys/TrichodermaIndex.cfm . Acesso em: 02 fev. 2009.

SAMUELS, G. J.; DODD, S. L.; GAMS, W.; CASTLEBURRY, L. A.; PETRINI, O. Trichoderma species associated with the green mold epidemic of commercially grown Agaricus bisporus. Mycologia, Lawrence, v. 94, n. 1, p.146-170, 2002.

SHALIN, S.; NARAYAN, K. P.; LATA.; KOTASTHANE, A. S. Genetic relatedness among Trichoderma isolates inhibiting a pathogenic fungi Rhizoctonia solani. African Journal of Biotechnology, Lagos, v. 5, n. 8, p.580-584, 2006.

SHARMA, K.; MISHRA, A. K.; MISRA, R. S. Morphological, biochemical and molecular characterization of Trichoderma harzianum isolates for their efficacy as biocontrol agents. Journal of Phytopathology, Hoboken, v. 157, n. 1, p.51-56, 2009. 